\title{
Variabilidade espacial de parâmetros de crescimento da mamoneira e de atributos físico-químicos em Neossolo ${ }^{1}$
}

\author{
Júlio J. N. Silva², Abelardo A. A. Montenegro², Ênio F. F. Silva², Robertson V. P. Fontes Júnior ${ }^{2} \&$ Ana P. N. Silva ${ }^{2}$
}

\section{RESU MO}

Objetivou-se, com este trabalho, avaliar a variabilidade espacial das variáveis de crescimento da cultura da mamoneira e sua relação com os atributos físicos e químicos em Neossolo flúvico, no Agreste de Pernambuco. Utilizou-se a cultivar BRS 188 - Paraguaçu que, segundo a literatura, se adequa às condições locais. O cultivo experimental foi conduzido na Fazenda Nossa Senhora do Rosário, Pesqueira, PE, em regime de sequeiro. Técnicas estatísticas e geoestatísticas foram utilizadas a fim de se observar o grau de dependência e a variabilidade espacial dos atributos de solo, granulometria, condutividade elétrica do extrato de saturação (CEes) e teor de sódio $(\mathrm{Na})$, bem como as variáveis de crescimento da cultura, diâmetro caulinar e altura das plantas. Todas as variáveis se ajustaram a uma distribuição Normal, com exceção do diâmetro caulinar aos 200 dias após a semeadura, e apresentaram de médio a baixo grau de dependência espacial. Dentre as variáveis estudadas apenas a CEes apresentou Efeito Pepita Puro (EPP), ajustando-se as demais, a modelos teóricos de semivariogramas experimentais. Os mapas de isolinhas produzidos permitiram observar regiões mais heterogêneas, principalmente nas áreas mais arenosas onde se verificou maior crescimento das plantas e nas quais um manejo localizado da área deve ser desenvolvido.

Palavras-chave: vale aluvial, geoestatística, Ricinus communis

\section{Spatial variability of growth parameters of castor bean crop and of physico-chemical attributes in Fluvisol}

\begin{abstract}
The aim of this study was to evaluate the potential of the castor bean crop in a Fluvisol of Pernambuco "Agreste". The research was conducted at the Nossa Senhora do Rosário Farm, Pesqueira-PE. The BRS 188 - Paraguaçu castor bean was cultivated, which, according to the literature, is suitable for the local conditions. The experiment was conducted under rainfed condition. Classical statistics and geostatistics techniques were applied to observe the degree of dependency for the attributes and the spatial variability of soil texture, electrical conductivity of saturation extract (CEes) and sodium ( $\mathrm{Na}$ ) content, as well as the crop stem diameter and height of the plants. All parameters adjusted to a Normal distribution, except stem diameter, at 200 days after sowing, showing a medium to low degree of spatial dependence. Among the studied variables only CEes showed pure nugget effect, adjusting the others to theoretical models of semivariograms. The produced contour maps allowed the observation of more heterogeneous areas, mainly in the most sandy area where better crop growth was verified and where a local management strategy must be developed.
\end{abstract}

Key words: alluvial valley, geostatistics, Ricinus communis

Parte da Dissertação de Mestrado do primeiro autor, apresentada à UFRPE

2 UFRPE, Rua Dom Manoel de Medeiros, s/n, Dois Irmãos, CEP 52171-900, Recife, PE. Fone: (81) 3320-6264. E-mail: juliojns1980@yahoo.com.br; monte@hotlink.com.br; enio.silva@dtr.ufrpe.br; rr_fontes@hotmail.com; anapaulaeng@yahoo.com.br 


\section{INTRODUÇÃO}

A busca mundial pela sustentabilidade ambiental, com base na substituição progressiva dos combustíveis minerais derivados do petróleo, responsáveis diretos pelo efeito estufa, por combustíveis renováveis de origem vegetal, dentre eles o biodiesel do óleo da mamona, criou uma perspectiva real para a expansão do seu cultivo em escala comercial, no semiárido brasileiro, principalmente na agricultura familiar, que já tem tradição no cultivo desta oleaginosa (Beltrão et al., 2005).

Neste cenário, a pequena agricultura, ou a agricultura familiar, praticada em vales aluviais, vem-se constituindo em importante fonte de renda para pequenas comunidades contribuindo, assim, para diminuir o êxodo rural. Os vales aluviais do semiárido apresentam elevado potencial para a pequena agricultura, embora sejam susceptíveis a processos de acúmulo de sais, tanto na zona não-saturada quanto na saturada, a depender, dentre outros fatores, da distribuição espacial de suas características hidráulicas. Em tais áreas, a não consideração da variabilidade espacial dos atributos do solo e de suas aptidões pode afetar significativamente os planos de manejo agrícola (Montenegro \& Montenegro, 2006).

No Brasil ainda são poucos os estudos que consideram a variabilidade espacial de atributos físicos em uma unidade de mapeamento de solo. O conhecimento da distribuição das propriedades do solo no campo é importante para o refinamento das práticas de manejo e avaliação dos efeitos da agricultura sobre a qualidade ambiental, servindo de base para a agricultura de precisão (Souza et al., 2004).

No que diz respeito à produção agrícola, as culturas recebem, de modo geral, um manejo convencional, no qual as práticas culturais são aplicadas uniformemente visto que se assume a homogeneidade dos fatores de produção, em todo o campo. O desconhecimento pontual ou localizado dos fatores de produção pode tornar as metas de produtividade impróprias e levar ao uso excessivo de insumos, conduzindo a uma produção ineficiente, com altos custos e danos ambientais; portanto, a variabilidade, nos aspectos produtivos e de desenvolvimento de uma cultura dentro do campo, pode ser devida às características do solo, clima ou induzida pelo manejo (Miranda et al., 2005).

Ressalta-se que em biossistemas a variabilidade está sempre presente, visto que se trabalha com indivíduos distintos em cada período de tempo (Cardoso et al., 2006), neste caso, a análise de crescimento não destrutiva entra como ferramenta importante, que avalia a eficiência do manejo adotado, razão pela qual é bastante utilizada por pesquisadores da área agrícola, uma vez que visa estudar o aumento dos fitossistemas sem destruir as plantas. Assim, os mesmos indivíduos podem ser mensurados durante o ciclo biológico, tendo como valores primários a altura de plantas, o diâmetro caulinar e a área foliar. Este método tem sido bastante utilizado para investigação do efeito de fenômenos ecológicos sobre o crescimento na adaptabilidade de espécies em ecossistemas diversos, efeito de competição de cultivares e influência de práticas agronômicas sobre o crescimento (Cardoso et al., 2006); portanto, as práticas de manejo utilizadas, profundidade do lençol freático, permeabilidade do solo, taxa de eva- potranspiração, chuvas, salinidade da água subterrânea e outros fatores hidrogeológicos, são os responsáveis pela variabilidade espacial de propriedades físicas e químicas dos solos (Chaves et al., 2005).

O primeiro passo para produzir culturas considerando-se a variabilidade espacial é a confecção de mapas de produtividade os quais permitem visualizar a variabilidade dos fatores de produção e da produtividade das culturas. A análise desses mapas e a correlação entre propriedades do solo e da cultura possibilitam decisões de manejo sobre irrigação e drenagem, plantio, variedades adaptadas, aplicação localizada de sementes, fertilizantes e corretivos, herbicidas e defensivos agrícolas, além de intensidade do preparo do solo (Miranda et al., 2005).

Objetivou-se, com este trabalho, avaliar a variabilidade espacial das variáveis de crescimento, altura de planta e diâmetro do caule da cultura da mamoneira buscando-se correlações com os atributos físicos e químicos em Neossolo Flúvico no Agreste de Pernambuco.

\section{MATERIAL E MÉTODOS}

A área de estudo está localizada na Fazenda Nossa Senhora do Rosário, a $230 \mathrm{~km}$ de Recife, PE, com coordenadas geográficas de $08^{\circ} 10^{\prime} \mathrm{S}$ e $35^{\circ} 11^{\prime} \mathrm{W}$, de latitude e longitude, respectivamente, e $650 \mathrm{~m}$ de altitude. O clima do local é classificado, segundo Köeppen, como BShw' semiárido quente, caatinga hiperxerófila, com temperatura média anual em torno de $27{ }^{\circ} \mathrm{C}$, umidade relativa média anual do ar de $73 \%$ e velocidade média do vento de $2,5 \mathrm{~m} \mathrm{~s}^{-1}$.

O plantio foi realizado em um vale aluvial da Bacia do Rio Ipanema, com tipo de solo classificado como Neossolo Flúvico, no período de 15 de março até 31 de outubro de 2007, com mamona cultivar BRS 188 - Paraguaçu, em uma área de $1444 \mathrm{~m}^{2}$ em espaçamento de 3 x $1 \mathrm{~m}$, perfazendo um stand de 480 plantas, em consórcio com feijão-caupi com espaçamento 0,5 x 0,5 m nas entrelinhas de mamona. A Tabela 1 mostra as condições de fertilidade do solo da área de estudo, que dispensaram adubação.

Tabela 1. Análise de fertilidade do solo da área de estudo. Pesqueira, PE, 2007

\begin{tabular}{|c|c|c|c|c|c|c|c|c|c|}
\hline $\mathrm{pH}$ & $\mathbf{P}$ & K & $\mathrm{Ca}$ & $\mathrm{Mg}$ & $\mathrm{Na}$ & Al & S & \multirow{2}{*}{$\begin{array}{l}\mathbf{V} \\
\%\end{array}$} & \multirow{2}{*}{$\begin{array}{l}\text { M.O. } \\
\mathrm{g} \mathrm{kg}^{-1}\end{array}$} \\
\hline$\left(\mathrm{H}_{2} \mathrm{O}\right)$ & $\mathrm{mg} \mathrm{dm}^{-3}$ & \multicolumn{6}{|c|}{$\mathrm{cmol}_{\mathrm{c}} \mathrm{dm}^{-3}$} & & \\
\hline 7,1 & 90,6 & 5,4 & 39,1 & 24,9 & 2,8 & 0,0 & 72,2 & 100 & 10,1 \\
\hline
\end{tabular}

O plantio foi manejado sem irrigação em virtude da distribuição regular das chuvas durante o período, que foi de um total de $397 \mathrm{~mm}$ em todo o ciclo. Doorenbos \& Pruitt (1977) apresentaram as fases fenológicas para diversas espécies de interesse agronômico, inclusive a mamoneira, quantificando e caracterizando os seus respectivos estádios de desenvolvimento. Na Tabela 2 estão descritas as fases fenológicas da cultura da mamoneira com suas respectivas durações em dias e o total precipitado em milímetros $(\mathrm{mm})$ por fase do experimento. 
Tabela 2. Fases fenológicas da cultura da mamoneira, duração aproximada de cada estádio de desenvolvimento e total precipitado por fase

\begin{tabular}{llcc}
\hline \multicolumn{1}{c}{ Estádio de desenvolvimento } & \multicolumn{1}{c}{ Caracterização do estádios } & $\begin{array}{c}\text { Duração } \\
\text { aproximada } \\
\text { (dias) }\end{array}$ & $\begin{array}{c}\text { Precipitação } \\
\text { (mm) }\end{array}$ \\
Estádio I - Fase inicial & $\begin{array}{l}\text { Germinação e crescimento inicial, quando a superfície do solo está coberta muito pouca ou } \\
\text { quase nada pela cultura. }\end{array}$ & 25 & 15 \\
Estádio II - Fase de crescimento & $\begin{array}{l}\text { Desde o final da fase inicial até se chegar a uma cobertura com sombreamento efetivo } \\
\text { completo. }\end{array}$ & 40 \\
Estádio III - Fase do período intermediário & $\begin{array}{l}\text { Desde o final da fase anterior até o momento de início da maturação, manifestada pela } \\
\text { descoloração das folhas ou sua queda }\end{array}$ & 65 & 137 \\
Estádio IV - Fase do período final & Do estádio anterior até a plena maturação ou colheita & 50 & 76 \\
\hline
\end{tabular}

Fonte: Doorenbos \& Pruitt (1977)

Realizaram-se análises de crescimento não destrutivas: diâmetro do caule, medido com paquímetro e altura aferida das plantas, com régua; ao todo, foram realizadas 10 medições nos seguintes períodos: 16, 32, 51, 63, 72, 81, 97, 133, 168 e 200 dias após a semeadura (DAS), sendo avaliadas 160 plantas em malha regular de $3 \times 3 \mathrm{~m}$.

No tocante à textura (areia, silte e argila), as amostras de solo foram retiradas nas camadas de 0-20, 20-40 e 40-60 cm, em uma malha de $6 \times 3 \mathrm{~m}$, perfazendo 80 pontos de coleta e 240 amostras.

Para avaliar os parâmetros químicos: CEes (condutividade elétrica no extrato saturado) e teor de sódio ( $\mathrm{Na}$ ), amostras de solo foram retiradas no início do plantio (30 DAS) nas camadas de $0-20$ e $20-40 \mathrm{~cm}$ e, no seu final na camada de 0-40 cm (230 DAS). Utilizou-se uma malha 6 x $6 \mathrm{~m}$, perfazendo 40 pontos de coleta totalizando 120 amostras.

Com esses pontos amostrais, analisaram-se a estrutura e a dependência espacial, através dos semivariogramas experimentais, em que a dependência espacial é definida pelo alcance (Ao), o erro cometido, devido ao espaçamento mínimo de amostragem, é definido pelo efeito pepita (Co) e o ponto em que toda semivariância da amostra é de influência aleatória, é definido pelo patamar (C+Co) (Vieira, 2000).

Realizou-se análise estatística descritiva através da avaliação de medidas de tendência central (média, mediana e moda) e dispersão (desvio padrão, variância, coeficiente de variação), e de aderência à distribuição Normal, segundo o teste de Kolmogorov-Smirnov, o qual mede a distância máxima entre os resultados de uma distribuição a ser testada e os resultados associados à distribuição hipoteticamente verdadeira (Gonçalves et al., 2001). Para a análise geoestatística utilizou-se a ferramenta GEO-EAS (Englund \& Sparks, 1992) e GS+ (Robertson, 1998). Testaram-se, após a obtenção dos semivariogramas experimentais, os modelos gaussiano, esférico e exponencial, sendo verificado se os erros padronizados apresentaram média próxima a zero e desvio-padrão próximo à unidade, segundo o critério de Jack-Knifing (Vauclin et al., 1983).

Analisaram-se para caracterização do grau de variabilidade os valores de coeficiente de variação (CV) dos atributos, conforme sugerido por Warrick \& Nielsen (1980), os quais consideram baixa variabilidade quando $\mathrm{CV}<12 \%$; média para o intervalo $12-60 \%$ e alta variabilidade quando $\mathrm{CV}>60 \%$. No tocante ao grau de dependência espacial, utilizou-se a classificação proposta por Cambardella et al. (1994), na qual determinado atributo pode ser conside- rado exibindo forte, moderada ou fraca dependência espacial, em função da relação entre o efeito pepita puro e o patamar do semivariograma ajustado. Valores inferiores a $25 \%$ caracterizam forte dependência espacial, entre 25 e $75 \%$ moderada, enquanto acima de $75 \%$, fraca dependência; enfim, para confecção dos mapas de isolinhas adotouse o software Surfer 7.0.

\section{RESULTADOS E DISCUSSÃO}

Os atributos físicos correspondentes às amostras coletadas nos 80 pontos na área de cultivo de mamona, nas camadas de $0-20 \mathrm{~cm}, 20-40 \mathrm{~cm}$ e $40-60 \mathrm{~cm}$, foram analisados por meio da estatística descritiva e se encontram na Tabela 3.

Com auxílio do triângulo textural descrito por Lemos \& Santos (1996) e de acordo com os valores texturais médios observados, o solo em questão foi classificado como textura franco-arenosa. Os coeficientes de variação (CVs) apresentaram valores de média variabilidade, conforme critério definido por Warrick \& Nielsen (1980). A mesma classificação foi encontrada por Vieira et al. (2007), para as frações areia, silte e argila, para solos franco-argilo-arenosos cultivados com pastagem de capim braquiária e grama batatais, respectivamente; outrossim, Lima et al. (2006) encontraram valores de média variabilidade para as frações argila e silte e baixa para a fração areia em solos franco-arenosos cultivados com mamão. Souza et al. (2004) constataram valores referentes à granulometria indicando variabilidade baixa para argila, média para silte e areia, respectivamente, em Latossolos cultivados com cana-de-açúcar.

Como salientado por Panosso et al. (2008) e Corá et al. (2004), em se tratando de dados naturais o ajuste a uma distribuição teórica é apenas aproximado. De acordo com Carvalho et al. (2009), a normalidade é recomendável sendo conveniente que a distribuição não apresente caudas muito alongadas, o que poderia comprometer os resultados; assim, a partir dos resultados da análise exploratória dos dados é possível admitir que essas variáveis apresentam distribuições suficientemente simétricas para o estudo geoestatístico. Os resultados do teste de Kolmogorov-Smirnov (KS), a nível de $5 \%$ de probabilidade, aplicado neste trabalho, corroboram com o fato de que a distribuição dos dados segue a curva Normal para todas as variáveis. Outros pesquisadores encontraram distribuição Normal para os atributos físicos do solo, na mesma área aluvial (Montenegro \& Montenegro, 2006). 
Tabela 3. Estatística clássica dos teores de areia, silte e argila

\begin{tabular}{|c|c|c|c|c|c|c|c|c|c|c|c|c|c|}
\hline Atributo & $\mathrm{X}(\%)$ & 5 & $\mathrm{CV}$ & Var & Curt & Q1 & Mín & Med & Máx & Q3 & EMáx & K-S & Dist \\
\hline \multicolumn{14}{|c|}{ Camada $0-20 \mathrm{~cm}$} \\
\hline Areia & 64,8 & 7,8 & 0,12 & 60,6 & $-0,87$ & 58,5 & 48,8 & 64,8 & 81,3 & 71,8 & 0,10 & 0,15 & $\mathrm{~N}$ \\
\hline Argila & 15,4 & 3,5 & 0,23 & 12,1 & $-1,10$ & 12,2 & 9,20 & 15,7 & 22,7 & 18,2 & 0,08 & 0,15 & $\mathrm{~N}$ \\
\hline Silte & 19,8 & 5,5 & 0,28 & 29,9 & $-0,20$ & 16,0 & 5,50 & 20,0 & 30,0 & 23,3 & 0,07 & 0,15 & $\mathrm{~N}$ \\
\hline \multicolumn{14}{|c|}{ Camada $20-40 \mathrm{~cm}$} \\
\hline Areia & 64,3 & 8,3 & 0,13 & 68,4 & $-0,6$ & 57,5 & 46,8 & 64,3 & 85,8 & 70,8 & 0,09 & 0,15 & $\mathrm{~N}$ \\
\hline Argila & 17,3 & 3,8 & 0,22 & 14,3 & $-0,5$ & 14,2 & 10,2 & 17,2 & 26,2 & 19,7 & 0,09 & 0,15 & N \\
\hline Silte & 18,4 & 5,4 & 0,29 & 28,9 & 0,0 & 15,0 & 4,00 & 18,0 & 33,0 & 22,1 & 0,07 & 0,15 & $\mathrm{~N}$ \\
\hline \multicolumn{14}{|c|}{ Camada $40-60 \mathrm{~cm}$} \\
\hline Areia & 68,4 & 9,1 & 0,13 & 85,6 & 0,512 & 3,76 & 43,8 & 68,8 & 89,3 & 72,8 & 0,08 & 0,15 & $\mathrm{~N}$ \\
\hline Argila & 16,0 & 4,1 & 0,26 & 17,1 & 0,2 & 13,2 & 7,74 & 13,2 & 27,2 & 18,5 & 0,10 & 0,15 & $\mathrm{~N}$ \\
\hline Silte & 15,6 & 5,6 & 0,36 & 31,7 & 0,29 & 12,5 & 3,00 & 12,5 & 31,5 & 19,0 & 0,08 & 0,15 & $\mathrm{~N}$ \\
\hline
\end{tabular}

X(\%) - Teor médio; S - Desvio padrão; CV - Coeficiente de variação; Var - Variância; Curt - Curtose; Q1 - 1o quartil; Mín - Mínimo; Méd - mediana; Máx - máximo; Q3 - 3o quartil; EMáx - Erro Máximo; K-S - Teste de Normalidade de Kolmogorov-Smirnov; Dist - Distribuição; N - Distribuição Normal

Encontram-se, na Tabela 4, os parâmetros dos semivariogramas ajustados, indicando o grau de variabilidade espacial dos atributos físicos. Na camada $0-20 \mathrm{~cm}$, o modelo esférico se ajustou adequadamente aos dados dos atributos areia e silte, com coeficiente de determinação $\left(R^{2}\right)$ de 0,98 e 0,94 , com grau de dependência espacial (GDE) de 0,98 e 0,85 , respectivamente; já o modelo exponencial se ajustou melhor ao atributo argila, com $\mathrm{R}^{2}$ de 0,93 e GDE de 0,77 o que, segundo Cambardella et al. (1994), pode ser considerado como de baixa dependência espacial. Nas camadas de 20-40 e 40-60 cm, o modelo esférico apresentou melhor comportamento, embora com $\mathrm{R}^{2}$ baixo, apresentando baixa dependência espacial.

O modelo que se ajustou com maior frequência aos dados granulométricos foi o esférico, juntamente com o exponencial. Bertolani et al. (2000) afirmam que são esses os modelos que mais se ajustam aos dados de atributos físicos do solo. Nos trabalhos de variabilidade espacial de características do solo é comum se encontrar ajuste dos semivariogramas a esses dois modelos (Souza et al., 2004).

Os valores do patamar apresentaram grande variabilidade entre os atributos seguindo, em ordem crescente de valores, argila, silte e areia; o mesmo ocorre em relação aos alcances, que foram mais acentuados na camada superficial
$(0-20 \mathrm{~cm})$; o silte apresentou maior valor $23,04 \mathrm{~m}$, seguido da areia e da argila 20,92 e 11,82 m, respectivamente. Este parâmetro indica a distância até onde os pontos amostrais estão correlacionados entre si, ou seja, os pontos localizados em uma área cujo raio seja o alcance, são mais semelhantes entre si do que os separados por distâncias maiores (Lima et al., 2006).

$\mathrm{Na}$ camada de solo de $20-40 \mathrm{~cm}$, os alcances foram menores em relação à camada de $0-20 \mathrm{~cm}$, com máximo de 5,69 m para o atributo areia e mínimo de 4,79 m para atributo silte; esta característica também foi observada na camada de 40-60 cm, cujo maior alcance foi de 7,11 m para argila e $6,3 \mathrm{~m}$ para silte, indicando maior descontinuidade na distribuição espacial das propriedades do solo na camada mais profunda (Souza et al., 2004). Este fato está de acordo com um importante conceito em gênese do solo, no qual o maior tempo relativo de exposição dos horizontes superficiais condiciona sua maior taxa de intemperismo (Montanari et al., 2008); Por outro lado, este conceito pode ter contribuído para aumentar o alcance da dependência espacial, caracterizando maior continuidade na distribuição das variáveis na camada mais superficial da área estudada, concordando com estudos de Souza et al. (2001) que trabalhando com malhas regulares espaçadas $50 \mathrm{~m}$, observa-

Tabela 4. Parâmetros dos semivariogramas dos teores de areia, silte e argila, nas três camadas estudadas $(0-20,20-40,40-60 \mathrm{~cm})$

\begin{tabular}{|c|c|c|c|c|c|c|c|c|}
\hline \multirow{2}{*}{ Atributos } & \multicolumn{6}{|c|}{ Parâmetros do Semivariograma } & \multicolumn{2}{|c|}{ VC } \\
\hline & Modelo & Co & $\mathrm{Co}+\mathrm{C}$ & Ao & $\mathbf{R}^{2}$ & GDE & Média & DesvPad. \\
\hline \multicolumn{9}{|c|}{ Camada $0-20 \mathrm{~cm}$} \\
\hline Areia & Esférico & 2,1 & 70,47 & 20,92 & 0,98 & 0,98 & 0,00 & 1,2 \\
\hline Argila & Exponencial & 3,33 & 14,75 & 11,82 & 0,93 & 0,77 & $-0,02$ & 0,76 \\
\hline Silte & Esférico & 5,2 & 34,27 & 23,04 & 0,94 & 0,85 & 0,01 & 1,12 \\
\hline \multicolumn{9}{|c|}{ Camada $20-40 \mathrm{~cm}$} \\
\hline Areia & Esférico & 10,3 & 67,25 & 5,69 & 0,36 & 0,85 & $-0,01$ & 0,93 \\
\hline Argila & Esférico & 2,08 & 13,77 & 5,07 & 0,18 & 0,85 & 0,02 & 0,96 \\
\hline Silte & Esférico & 5,76 & 28,98 & 4,79 & 0,3 & 0,8 & $-0,01$ & 0,87 \\
\hline \multicolumn{9}{|c|}{ Camada $40-60 \mathrm{~cm}$} \\
\hline Areia & Esférico & 3,6 & 88,63 & 6,76 & 0,61 & 0,96 & 0,03 & 1,08 \\
\hline Argila & Esférico & 0,01 & 18,15 & 7,11 & 0,73 & 1 & $-0,03$ & 1,15 \\
\hline Silte & Esférico & 5,92 & 33,59 & 6,3 & 0,51 & 0,82 & $-0,02$ & 0,69 \\
\hline
\end{tabular}

Co - Efeito pepita; Co+C - Patamar; Ao - Alcance; R² - Coeficiente de Determinação; GDE - Grau de Dependência Espacial; VC - Validação Cruzada; DesvPad - Desvio Padrão 
ram que a camada superficial de $0-20 \mathrm{~cm}$, apresentou menor variabilidade.

Apesar de alguns atributos apresentarem $\mathrm{R}^{2}$ baixos, os semivariogramas ajustados foram validados através da metodologia de Jack-knifing (Vauclin et al., 1983), produzindo resíduos com médias entre -0,03 e 0,03 e desvios-padrão entre 0,69 e 1,2. Queiroz et al. (1999) relatam que a principal finalidade da modelagem da estrutura da dependência espacial, através do semivariograma, é possibilitar a estimativa por interpolação dos valores da variável para locais não amostrados e criar mapas de isovalores com maior precisão. A Figura 1 ilustra o mapeamento do atributo areia, mediante krigagem, com o respectivo semivariograma experimental, para a camada de $0-20 \mathrm{~cm}$.

O mapa dos teores de areia apresenta regiões com maiores valores, acima de $60 \%$, na parte superior esquerda, indicando diminuição na região central para a região direita. É importante observar o comportamento do grau de dependência espacial, que reflete tanto a variabilidade na microescala (menor que distância mínima de separação entre os pontos) quanto as incertezas do método de determinação em laboratório. Verificam-se altos valores de GDE para as camadas 0-20 cm e 40-60 cm, com reduções para a camada de 20-40 cm devido, possivelmente, à influência de tratos culturais na camada superior, combinada com a ausência de fatores naturais de suavização, tais como chuvas e escoamentos superficiais.

A condutividade elétrica média do extrato de saturação
(CEes) inicial, antes do período chuvoso, foi igual a $1,48 \mathrm{dS} \mathrm{m}^{-1}$ para a camada de $0-20 \mathrm{~cm}$, e a $0,65 \mathrm{dS} \mathrm{m}^{-1}$ para a camada de 20-40 cm; já a CEes no final da estação chuvosa está representada pela camada de $0-40 \mathrm{~cm}$ cujo valor médio foi de $0,96 \mathrm{dS} \mathrm{m}^{-1}$. O período de início e final da estação chuvosa corresponde também ao início e final do ciclo da cultura, aos 200 DAS (Tabela 5).

Com base nos dados de CEes médios, os quais indicam o nível de sais, pode-se afirmar que não ocorrem problemas devido à presença de sais, ou seja, os solos nas áreas amostradas classificados como não salinos, apresentaram valores de CEes entre 0-4 dS m${ }^{-1}$, segundo Chaves et al. (2005). De acordo com o teste de Kolmogorov-Smirnov, a 5\% de probabilidade as amostras seguem uma distribuição Normal.

Seguindo a classificação de Warrick \& Nielsen (1980), verifica-se que CEes referentes às camadas 0-20; 20-40 e $0-40 \mathrm{~cm}$ apresentam média variabilidade, com CV entre 34 a $36 \%$; entretanto se observam alguns pontos com valores quase duas vezes acima da média, em todas as camadas de solo estudadas atribuindo, assim, caráter heterogêneo ao solo da área, o que é típico de solos aluvionais. Esta heterogeneidade pode ser imputada aos processos de formação inerentes a esses solos, que ocorrem pela acumulação e distribuição desuniformes de sucessivos depósitos de materiais oriundos de outros lugares, proporcionados pela posição topográfica que ocupam, além do manejo a que são submetidos (Souza et al., 2000).

$\mathrm{Na}$ análise de semivariogramas, nenhum modelo se ajustou
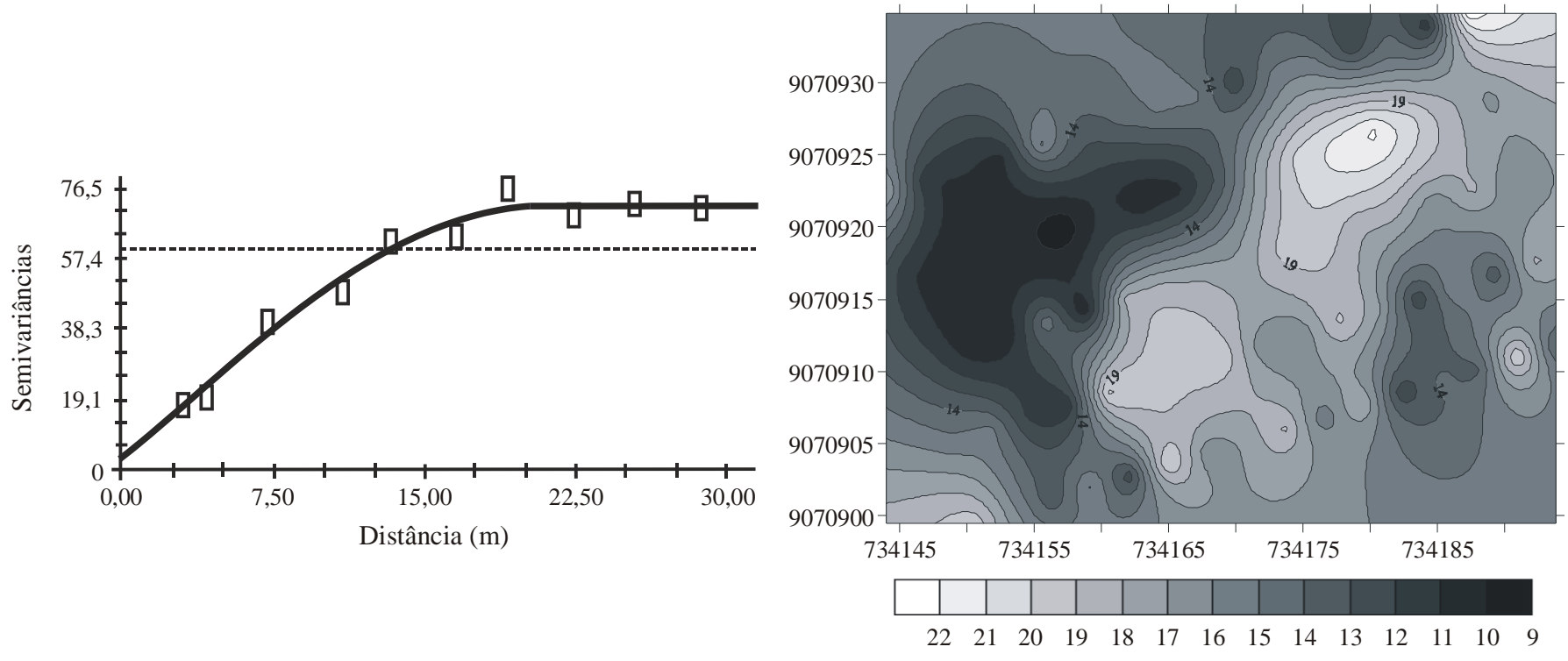

Figura 1. Semivariograma e mapa de isolinhas para o atributo areia na camada de $0-20 \mathrm{~cm}$

Tabela 5. Estatística clássica da condutividade elétrica do extrato de saturação (CEes) em dS m-1 no início da estação chuvosa nas camadas de 0-20 cm e 20-40 cm, e no final da estação chuvosa, na camada de 0-40 cm

\begin{tabular}{|c|c|c|c|c|c|c|c|c|c|c|c|c|c|}
\hline Atributo & $X\left(d S m^{-1}\right)$ & 5 & $\mathrm{CV}$ & Var & Curt & Q1 & Mín & Med & Máx & Q3 & EMáx & K-S & Dist \\
\hline CEes 0-20 & 1,48 & 0,53 & 0,36 & 0,28 & 4,01 & 1,22 & 0,59 & 1,375 & 3,32 & 1,595 & 0,16 & 0,22 & $N$ \\
\hline CEes 20-40 & 0,65 & 0,22 & 0,34 & 0,05 & 1,70 & 0,51 & 0,35 & 0,605 & 1,3 & 0,702 & 0,18 & 0,22 & $N$ \\
\hline CEes $0-40$ & 0,96 & 0,35 & 0,36 & 0,12 & 7,15 & 0,73 & 0,30 & 0,90 & 2,41 & 1,14 & 0,11 & 0,22 & $\mathrm{~N}$ \\
\hline
\end{tabular}

X - Média; S - Desvio padrão; CV - Coeficiente de variação; Var - Variância; Curt - Curtose; Q1 - 1o quartil; Mín - Mínimo; Med - mediana; Máx - máximo; Q3 - 3o quartil; EMáx - Erro Máximo; K-S - Teste de Normalidade de Kolmogorov-Smirnov; Dist - Distribuição, N - Distribuição Normal 
aos dados de CEes, segundo critério de Jack-Knifing (Vauclin et al., 1983), observando-se ausência de dependência espacial para todas as camadas e períodos, caracterizando assim Efeito Pepita Puro (EPP) (Figura 2), segundo critério de Cambardella et al, (1994). Souza et al. (2008), trabalhando com solos aluviais em um lote irrigado da Fazenda Nossa Senhora do Rosário, cultivado com cenoura, estudaram a variabilidade espacial da CEes, em duas camadas de solo 0-20 e 20-40 cm, antes e depois do ciclo da cultura, e também obtiveram EPP, exceto na última camada no final do ciclo, com alcance entre 7,95 e 11 m; já Souza et al. (2000), mapeando a CEes de solos aluvionais no Agreste paraibano, encontraram alcances com valores entre 25 e $40 \mathrm{~m}$.

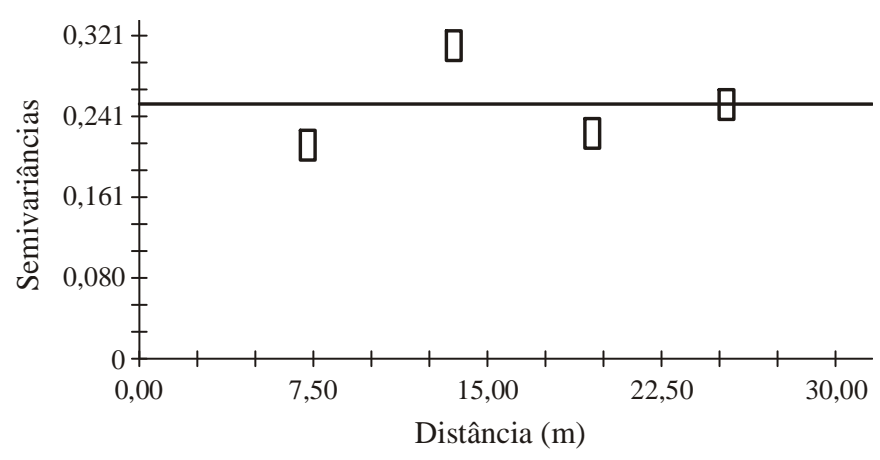

Figura 2. Semivariograma da condutividade elétrica do extrato de saturação (CEes) na camada de $0-20 \mathrm{~cm}$

Geralmente, o teor de Na do solo é expresso em percentual de sódio trocável (PST), ou relação de adsorção de sódio (RAS), que depende dos teores observados de $\mathrm{Na}$ e dos cátions cálcio e magnésio; entretanto, este trabalho se refere apenas aos teores de $\mathrm{Na}$ em mmolc $\mathrm{L}^{-1}$. A concentração média de $\mathrm{Na}$ do extrato de saturação inicial, antes do período chuvoso, foi igual $4,32 \mathrm{mmolc}^{-1}$, para a camada de $0-20 \mathrm{~cm}$, e de $3,24 \mathrm{mmolc} \mathrm{L}^{-1}$, para a camada de 0-40 cm; já a concentração de Na do final da estação chuvosa foi $4,27 \mathrm{mmol} \mathrm{L}^{-1}$, para a camada de $0-40 \mathrm{~cm}$; com base nesses resultados, pode-se afirmar que os solos nas áreas amostradas são classificados como não sódicos, segundo Chaves et al. (2005). De acordo com o teste de Kolmogorov-Smirnov, a $5 \%$ de probabilidade, as amostras seguem uma distribuição Normal (Tabela 6).

Seguindo a classificação de Warrick \& Nielsen (1980), verifica-se que os teores de $\mathrm{Na}$ referentes às camadas $0-20$; 20-40 e $0-40 \mathrm{~cm}$, mostram média variabilidade, com CV entre 25 a $54 \%$, diferindo de Chaves et al. (2005) que encontraram valores de CV acima de $100 \%$ (alta variabilidade) para $\mathrm{Na}$, nos solos dos perímetros irrigados de São Gonçalo e Arcoverde, no município de Condado,PB.

$\mathrm{Na}$ Tabela 7 se encontram os parâmetros dos semivariogramas experimentais das variáveis analisadas e os modelos ajustados para os casos que apresentaram dependência espacial. $\mathrm{Na}$ análise de semivariogramas, o modelo exponencial foi o que melhor se ajustou aos dados na camada de 0-20 cm, o gaussiano para a camada de $20-40 \mathrm{~cm}$ e o esférico para o final da estação chuvosa $(0-40 \mathrm{~cm})$. Os modelos foram validados segundo critério de Jack-Knifing (Vauclin et al., 1983), com média entre -0,012 e 0,003 e desvio padrão variando entre 0,89 e 1,015. Observa-se, também, baixo grau de dependência espacial para as demais camadas e períodos, com GDE de 0,04, segundo critério de Cambardella et al. (1994). Apesar de uma amplitude considerável nos valores de $\mathrm{R}^{2}$, os semivariogramas foram validados. Os alcances (Ao) variaram de 7,82 a 43,66 m, para as camadas de $20-40$ e $0-20 \mathrm{~cm}$, respectivamente. Souza et al. (2008) estudaram a variabilidade espacial da PST, em duas camadas 0-20 e 20-40 cm, antes e depois do ciclo da cultura da cenoura, no município de Pesqueira, PE, e obtiveram valores para os alcances entre 7,67 e 33,91 m; já Souza et al. (2000), mapeando a PST de solos aluvionais no Agreste paraibano, encontraram alcances com valores entre 20 e $35 \mathrm{~m}$.

Pode-se verificar, na Tabela 8 , as análises de crescimento não destrutivas, referentes aos parâmetros altura de plantas e diâmetro caulinar, da cultura da mamona. Observa-se pequena diferença entre médias e medianas das variáveis, in-

Tabela 6. Estatística clássica da concentração de sódio ( $\mathrm{Na}$ ) em mmolc L-1 ${ }^{-1}$ no início da estação chuvosa, nas camadas de 0-20 cm e 20-40 cm, e no final da estação chuvosa, na camada de $0-40 \mathrm{~cm}$

\begin{tabular}{cccccccccccccc}
\hline $\begin{array}{c}\text { Camadas } \\
(\mathbf{c m})\end{array}$ & $\begin{array}{c}\mathbf{X} \\
\mathbf{m m o l}_{\mathbf{~}} \mathbf{L}^{-1} \mathbf{)}\end{array}$ & $\mathbf{S}$ & $\mathbf{C V}$ & Var & Curt & Q1 & Min & Med & Máx & Q3 & Emáx & K-S & Dist \\
$0-20$ & 4,32 & 2,35 & 0,54 & 5,51 & 1,83 & 2,92 & 1,01 & 3,80 & 10,89 & 4,81 & 0,08 & 0,22 & $\mathrm{~N}$ \\
$20-40$ & 3,24 & 1,07 & 0,33 & 1,14 & 0,82 & 2,54 & 1,62 & 2,95 & 5,93 & 3,64 & 0,06 & 0,22 & $\mathrm{~N}$ \\
$0-40$ & 4,27 & 1,11 & 0,25 & 1,22 & $-0,50$ & 3,77 & 2,05 & 4,38 & 6,53 & 5,41 & 0,07 & 0,22 & $\mathrm{~N}$ \\
\hline
\end{tabular}

X - Média; S - Desvio padrão; CV - Coeficiente de variação; Var - Variância; Curt - Curtose; Q1 - 1ํ quartil; Mín - Mínimo; Med - mediana; Máx - máximo; Q3 - 30 quartil; EMáx - Erro Máximo; K-S - Teste de Normalidade de Kolmogorov-Smirnov; Dist - Distribuição; N - Distribuição Normal

Tabela 7. Parâmetros dos semivariogramas da concentração de sódio ( $\mathrm{Na}$ ), no início da estação chuvosa, nas camadas de 0-20 cm e 20-40 cm e no final da estação chuvosa, na camada de $0-40 \mathrm{~cm}$

\begin{tabular}{|c|c|c|c|c|c|c|c|c|}
\hline \multirow{2}{*}{ Camadas $(\mathrm{cm})$} & \multicolumn{6}{|c|}{ Parâmetros do semivariograma } & \multicolumn{2}{|c|}{ VC } \\
\hline & Modelo & Co & $\mathrm{Co}+\mathrm{C}$ & Ao & $\mathbf{R}^{2}$ & GDE & Média & Desv \\
\hline $0-20$ & Exponencial & 3,28 & 9,34 & 43,66 & 0,87 & 0,87 & 0,003 & 0,893 \\
\hline $20-40$ & Gaussiano & 0,06 & 1,22 & 7,82 & 0,04 & 0,04 & $-0,006$ & 1,021 \\
\hline $0-40$ & Esférico & 0,01 & 1,34 & 12,84 & 0,02 & 0,04 & $-0,012$ & 1,015 \\
\hline
\end{tabular}

Co - Efeito pepita; Co+C - Patamar; Ao - Alcance; R² - Coeficiente de Determinação; GDE - Grau de Dependência Espacial; VC - Validação Cruzada; DesvPad - Desvio Padrão 
Tabela 8. Estatística descritiva para as variáveis de crescimento altura de plantas e diâmetro caulinar, durante o ciclo da mamona

\begin{tabular}{|c|c|c|c|c|c|c|c|c|c|c|c|c|c|}
\hline DAS & $\bar{x}$ & 5 & $\mathrm{CV}$ & Var & Curt & Q1 & Mín & Med & Máx & Q3 & E Máx & K-S & Dist \\
\hline \multicolumn{14}{|c|}{ Altura de plantas $(\mathrm{cm})$} \\
\hline 16 & 11,01 & 2,52 & 0,23 & 6,37 & $-0,25$ & 9,5 & 5 & 11 & 17 & 13 & 0,09 & 0,11 & N \\
\hline 37 & 30,91 & 10,52 & 0,34 & 110,68 & $-0,35$ & 23 & 11 & 30 & 63 & 38,25 & 0,07 & 0,11 & $\mathrm{~N}$ \\
\hline 51 & 69,75 & 21,12 & 0,30 & 445,94 & $-0,62$ & 55 & 26 & 69 & 124 & 86,5 & 0,05 & 0,11 & $\mathrm{~N}$ \\
\hline 63 & 90,57 & 23,58 & 0,26 & 556,25 & $-0,04$ & 75 & 33 & 90 & 150 & 105 & 0,04 & 0,11 & $\mathrm{~N}$ \\
\hline 72 & 132,39 & 27,00 & 0,20 & 728,75 & 4,36 & 120 & 14 & 134,5 & 224 & 150 & 0,09 & 0,11 & $\mathrm{~N}$ \\
\hline 81 & 194,69 & 21,13 & 0,11 & 446,65 & 0,26 & 182 & 132 & 193 & 259 & 210 & 0,06 & 0,11 & $\mathrm{~N}$ \\
\hline 97 & 239,24 & 20,67 & 0,09 & 427,19 & 0,15 & 225 & 180 & 240 & 300 & 255 & 0,06 & 0,11 & N \\
\hline 133 & 299,44 & 31,61 & 0,11 & 999,05 & $-0,51$ & 275 & 225 & 300 & 375 & 321,25 & 0,05 & 0,11 & $\mathrm{~N}$ \\
\hline 168 & 321,94 & 32,7 & 0,10 & 1069,18 & $-0,34$ & 300 & 235 & 320 & 400 & 350 & 0,08 & 0,11 & $\mathrm{~N}$ \\
\hline 200 & 332,69 & 32,22 & 0,10 & 1038,33 & $-0,34$ & 310 & 250 & 335 & 410 & 356,25 & 0,07 & 0,11 & $\mathrm{~N}$ \\
\hline \multicolumn{14}{|c|}{ Diâmetro caulinar $(\mathrm{mm})$} \\
\hline 37 & 9,08 & 3,3 & 0,36 & 10,87 & 0,81 & 6,48 & 4 & 8,95 & 20 & 11 & 0,09 & 0,11 & $\mathrm{~N}$ \\
\hline 51 & 20,66 & 6,08 & 0,29 & 37,01 & $-0,67$ & 16 & 10 & 20 & 35 & 25 & 0,08 & 0,11 & $\mathrm{~N}$ \\
\hline 63 & 26,04 & 6,17 & 0,24 & 38,07 & $-0,1$ & 22 & 13 & 26 & 42 & 30 & 0,05 & 0,11 & $\mathrm{~N}$ \\
\hline 72 & 33,97 & 6,29 & 0,19 & 39,5 & 0,25 & 30 & 20 & 34 & 53 & 38 & 0,09 & 0,11 & $\mathrm{~N}$ \\
\hline 81 & 41,38 & 5,96 & 0,14 & 35,47 & 0,43 & 38 & 27 & 42 & 62 & 45 & 0,06 & 0,11 & $\mathrm{~N}$ \\
\hline 97 & 47,76 & 7,27 & 0,15 & 52,86 & 1,03 & 43 & 29 & 46,5 & 75 & 52 & 0,09 & 0,11 & $\mathrm{~N}$ \\
\hline 133 & 54,98 & 7,98 & 0,15 & 63,74 & 0,58 & 49 & 33 & 54 & 80 & 59 & 0,11 & 0,11 & $\mathrm{~N}$ \\
\hline 168 & 61,38 & 9,44 & 0,15 & 89,14 & $-0,06$ & 54 & 39 & 60 & 90 & 68 & 0,09 & 0,11 & $\mathrm{~N}$ \\
\hline 200 & 65,64 & 10,55 & 0,16 & 110,59 & 0,41 & 58 & 42 & 64,5 & 100 & 73 & 0,11 & 0,11 & $\mathrm{~N}^{*}$ \\
\hline
\end{tabular}

X - Média; S - Desvio padrão; CV - Coeficiente de variação; Var - Variância; Curt - Curtose; Q1 - 1o quartil; Mín - Mínimo; Med - mediana; Máx - máximo; Q3 - 3o quartil; EMáx - Erro Máximo; K-S - Teste de Normalidade de Kolmogorov-Smirnov; Dist - Distribuição; N - Distribuição Normal

dicando distribuições simétricas e normalidade, de acordo com o teste de Kolmogorov-Smirnov, com exceção do diâmetro caulinar aos 200 dias após a semeadura (DAS).

A variável altura de plantas apresenta valores de coeficiente de variação (CV) de até $20 \%$ aos 72 (DAS), indicando média variabilidade, segundo Warrick \& Nielsen (1980). Para períodos posteriores, este valor cai para menos de $12 \%$, indicando baixa variabilidade espacial; no tocante à variável diâmetro caulinar, observa-se que houve média variabilidade espacial em todo o ciclo da cultura, com $\mathrm{CV}$ variando entre 14 e $36 \%$.

Diversos autores vêm avaliando o crescimento de plantas de mamona, investigando seu comportamento sob diferentes condições de clima, solo, e dotação hídrica. Beltrão et al. (2004), trabalhando com as cultivares de mamona Nordestina e Paraguaçu em regime de sequeiro, em solo argilo-arenoso no Estado de Ceará, para o ano agrícola de 2003, encontraram altura de plantas de 146,2 e 194,8 cm e diâmetro caulinar de 33,7 e 35,8 cm, respectivamente. Já Guimarães et al. (2008), observando o crescimento inicial da variedade Nordestina aos 120 dias após a germinação sob quatro fontes de fertilizantes nitrogenados (uréia, esterco bovino, torta de mamona e biossólido) em casa de vegetação, e em Neossolo Regolítico, encontraram valores para altura de plantas da ordem 37,00; 49,56; 49, 11 e 40,61 cm, respectivamente. Outrossim, Nascimento et al. (2006), utilizando três doses de biossólido com 0; 75 e $150 \mathrm{~kg} \mathrm{ha}^{-1}$ de $\mathrm{N}$ e irrigação com água residuária e água de abastecimento, com a variedade Nordestina, em lisímetros de drenagem com capacidade de $0,5 \mathrm{~m}^{3}$, observaram que o crescimento das plantas se ajustou a um modelo não linear, com comportamento exponencial, e $\mathrm{R}^{2} \mathrm{de}$ 0,998 e 0,981, para altura de plantas e diâmetro caulinar, respectivamente. De acordo com os modelos pode-se, por exem- plo, verificar que, para os dias 51, 97 e 168, adotados no experimento deste artigo, a altura da cultura e o diâmetro do caule foram $(61,41 ; 14,13) ;(64,73 ; 17,89)$ e $(64,85 ; 18,22 \mathrm{~cm})$, respectivamente, para o tratamento água de abastecimento sem adubação podendo-se verificar valores de crescimento superiores para o experimento aqui analisado (Tabela 8).

Lima et al. (2007), avaliando o crescimento da mamoneira variedade Nordestina em Neossolo Regolítico, na ausência e presença de matéria orgânica, observaram um aumento de 95\% em altura de plantas, 357\% em área foliar, 528\% em massa seca da parte aérea e $494 \%$ em massa seca de raízes, para as condições de casa vegetação e adoção de matéria orgânica, aos 60 dias após o plantio.

Lima et al. (2004), trabalhando com a variedade Nordestina cultivada em vasos, em casa de vegetação, com três diferentes solos (Latossolo Vermelho-Amarelo distrófico (LVAd), Latossolo Vermelho-Amarelo eutrófico (LVAe) e Chernossolo Rêndzico Litólico (MDI)), associados a seis valores de condutividade elétrica $(0,5 ; 1,0 ; 1,5 ; 2,0 ; 2,5$ e 3,0 $\mathrm{dS} \mathrm{m}^{-1}$ ) observaram, aos 50 dias após o plantio, que a altura de plantas sofreu influência negativa do aumento da salinidade no LVAe, reduzindo de $36,93 \mathrm{~cm}$ para $26,87 \mathrm{~cm}$ nas concentrações de 0,5 para $3,0 \mathrm{dS} \mathrm{m}^{-1}$, respectivamente; já para o diâmetro de caule o LVAd apresentou maior sensibilidade à salinidade, principalmente na $\mathrm{CE}$ de $1,5 \mathrm{dS} \mathrm{m}^{-1}$, obtendo-se valor de $1,67 \mathrm{~cm}$.

Oliveira et al. (2006) verificaram o efeito da irrigação com água de diferentes salinidades, nas concentrações de 0, 2, 4 e $6 \mathrm{dS} \mathrm{m}^{-1}$, no crescimento inicial de mamoneira cultivado em vasos aos 64 dias após a semeadura. Associou-se a diferentes teores de esterco bovino, adicionados a um Argissolo Vermelho amarelo, nas proporções de solo: esterco de 1:0, $3: 1,2: 1,1: 1$, tendo demonstrado que, para o diâmetro de 
caule e altura de plantas, o tratamento sem esterco diferiu dos demais, juntamente com a salinidade de $6 \mathrm{dS} \mathrm{m}^{-1}$, contribuindo negativamente para o desempenho da cultura, iguais a 4,67 e 25,5 cm, respectivamente. Já Almeida Júnior et al. (2009), trabalhando em vasos com este mesmo solo e observando o efeito de doses de fósforo na ordem de $0,3,6$, 9, 13 e $15 \mathrm{~g}$ planta $^{-1}$, no crescimento inicial da mamoneira variedade Nordestina, observaram resposta positiva da altura de plantas e do diâmetro do caule até a dose de $9 \mathrm{~g} \mathrm{planta}^{-1}$, de 110 e $18 \mathrm{~cm}$ respectivamente, decrescendo a partir desta. Tal comportamento pode ser explicado uma vez que a maioria das culturas, inclusive mamona, recebe um manejo convencional, isto é, a área toda recebe o mesmo manejo agronômico, principalmente a nível de pequeno agricultor, na qual práticas culturais são aplicadas uniformemente haja vista que se assume homogeneidade dos fatores de produção (Miranda et al., 2005). Mantovani et al. (1998) descrevem que a variabilidade de um campo agrícola influencia fatores de desenvolvimento e de produção das culturas ligados à disponibilidade de nutrientes, suprimento de água e, consequentemente, ao ambiente em que estão localizadas as raízes. Miranda et al. (2005) também relatam que a variabilidade no estande das culturas está diretamente relacionada com os fatores edáficos, como propriedades físicas, químicas e biológicas, fatores climatológicos, como precipitação e de manejo, como aplicações desuniformes de sementes, fertilizantes e corretivos.

Observando a Tabela 9, vê-se que todas as variáveis de crescimento analisadas no decorrer do ciclo da cultura da mamona apresentaram grau de dependência espacial (GDE), variando de 50 a $96 \%$, caracterizando dependência entre baixa e média, segundo Cambardella et al. (1994).
Ocorreu alta amplitude entre os alcances (Ao) observados para os dois parâmetros durante o ciclo da cultura, chegando a $1,14 \mathrm{~m}$ aos 81 DAS e $28,91 \mathrm{~m}$ aos $200 \mathrm{DAS}$, para a altura das plantas e a 4,35 $\mathrm{m}$ aos 72 DAS e $21,89 \mathrm{~m}$ aos 168 DAS para o diâmetro caulinar. Trabalhos semelhantes com parâmetros relacionados à cultura, também foram realizados por Miranda et al. (2005) que, estudando peso comercial de frutos de melão, encontraram alcances variando entre 30 e 67,3 m em Argissolos e entre 30 e 58,3 m em Latossolos, respectivamente. Assumpção et al. (2007), mapeando a produtividade de soja com e sem manejo químico localizado durante as safras de 1999 a 2001, encontraram alcances variando de 48 a $62,3 \mathrm{~m}$ e de 28,88 a 40,98 m, respectivamente; já Frogbrook et al. (2002) ajustaram alcances com 199,5, 75,3 e $103 \mathrm{~m}$ para produtividade, clorose foliar e incidência de ervas daninhas em cultivo de cereal.

Os modelos de semivariogramas que se ajustaram aos dados experimentais deste trabalho foram o exponencial, esférico e gaussiano, todos validados segundo o critério de Jack-Knifing (Vauclin et al., 1983), apresentando erros padronizados com média variando entre -0,009 e 0,010 e desvio-padrão entre 0,91 a 1,00 para o parâmetro altura de planta; e para diâmetro caulinar, valores médios entre -0,003 e 0,008 , com desvio entre 0,91 e 1,14 , respectivamente.

Observa-se, nos mapas, que o maior desenvolvimento vegetativo evidenciado pelos parâmetros diâmetro caulinar e altura de plantas, se situa na região central da área de cultivo, a qual coincide com os valores de menor condutividade elétrica e menores teores de areia.

A Figura 3A e B mostra os semivariogramas e os mapas de isolinhas para altura de plantas e diâmetro caulinar, aos 200 DAS.

Tabela 9. Parâmetros dos semivariogramas do desenvolvimento da cultura da mamona: altura de plantas e diâmetro caulinar

\begin{tabular}{|c|c|c|c|c|c|c|c|c|}
\hline \multirow{2}{*}{ DAS } & \multicolumn{6}{|c|}{ Parâmetros do Semivariograma } & \multicolumn{2}{|c|}{ VC } \\
\hline & Modelo & Co & $\mathrm{Co}+\mathrm{C}$ & Ao & $\mathbf{R}^{2}$ & GDE & Média & DesvPad \\
\hline \multicolumn{9}{|c|}{ Altura das plantas $(\mathrm{cm})$} \\
\hline 16 & Esférico & 1,46 & 6,37 & 4,28 & 0,34 & 0,77 & $-0,009$ & 0,92 \\
\hline 37 & Gaussiano & 26,60 & 114,10 & 5,02 & 0,91 & 0,87 & $-0,006$ & 0,99 \\
\hline 51 & Exponencial & 121,00 & 459,90 & 4,37 & 0,89 & 0,74 & 0,004 & 0,99 \\
\hline 63 & Exponencial & 163,00 & 580,40 & 4,88 & 0,72 & 0,96 & $-0,003$ & 0,91 \\
\hline 72 & Gaussiano & 175,00 & 742,80 & 4,68 & 0,76 & 0,81 & 0,010 & 0,93 \\
\hline 81 & Exponencial & 123,20 & 437,40 & 1,14 & 0,08 & 0,72 & 0,001 & 0,87 \\
\hline 97 & Exponencial & 221,10 & 450,20 & 5,57 & 0,89 & 0,51 & 0,009 & 1,00 \\
\hline 133 & Esférico & 523,00 & 1161,00 & 28,55 & 0,98 & 0,55 & 0,007 & 0,95 \\
\hline 168 & Exponencial & 419,00 & 1638,00 & 21,99 & 0,99 & 0,64 & 0,006 & 0,94 \\
\hline 200 & Esférico & 371,00 & 1288,00 & 28,91 & 0,98 & 0,71 & 0,002 & 0,94 \\
\hline \multicolumn{9}{|c|}{ Diâmetro caulinar (mm) } \\
\hline 37 & Esférico & 1,99 & 10,97 & 8,81 & 0,79 & 0,82 & 0,001 & 1,07 \\
\hline 51 & Gaussiano & 7,40 & 38,08 & 5,80 & 0,8 & 0,81 & $-0,002$ & 1,01 \\
\hline 63 & Exponencial & 12,66 & 40,65 & 4,85 & 0,93 & 0,69 & 0,008 & 1,11 \\
\hline 72 & Exponencial & 20,45 & 42,84 & 4,35 & 0,87 & 0,52 & $-0,002$ & 1,14 \\
\hline 81 & Exponencial & 21,46 & 42,93 & 13,24 & 0,96 & 0,50 & 0,004 & 1,14 \\
\hline 97 & Exponencial & 26,10 & 60,87 & 7,08 & 0,93 & 0,57 & $-0,002$ & 0,94 \\
\hline 133 & Exponencial & 29,20 & 69,63 & 8,70 & 0,93 & 0,58 & $-0,001$ & 0,91 \\
\hline 168 & Esférico & 36,90 & 104,3 & 21,89 & 0,96 & 0,65 & $-0,003$ & 0,94 \\
\hline 200 & Esférico & 42,50 & 133,7 & 20,24 & 0,95 & 0,68 & $-0,001$ & 0,91 \\
\hline
\end{tabular}

DAS - Dias após a semeadura; Co - Efeito pepita; Co+C - Patamar; Ao - Alcance; R² - Coeficiente de Determinação; GDE - Grau de Dependência Espacial; VC - Validação Cruzada; DesvPad Desvio Padrão 
A.

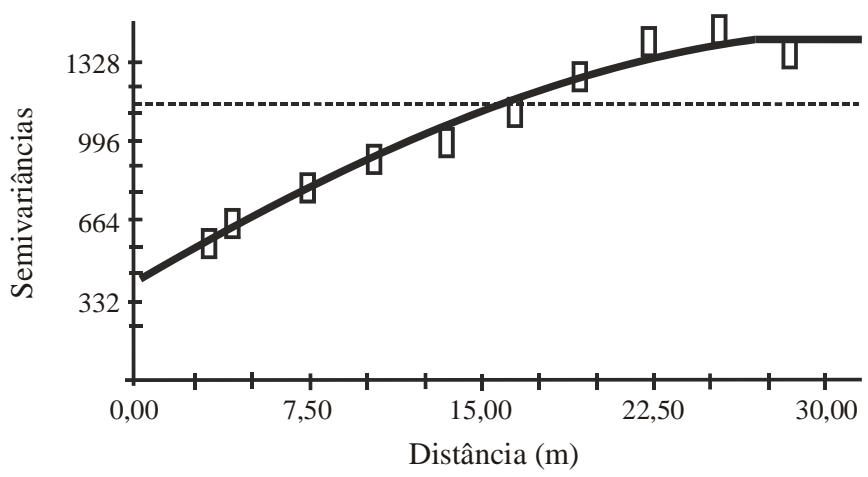

B.

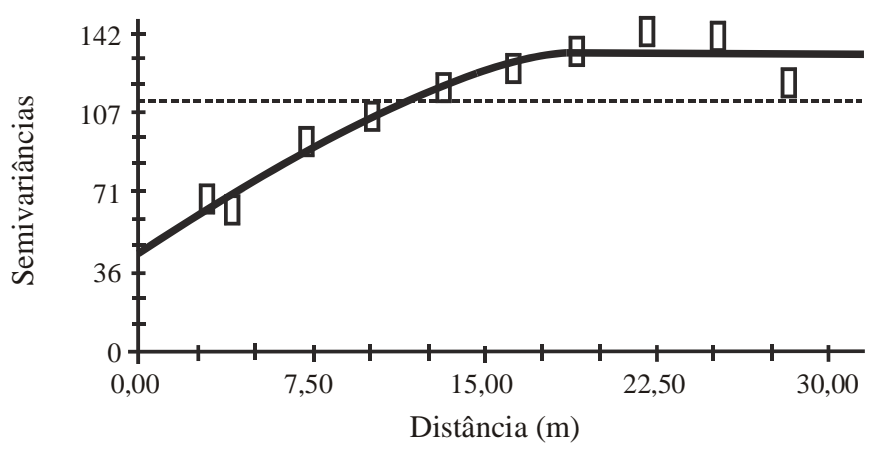

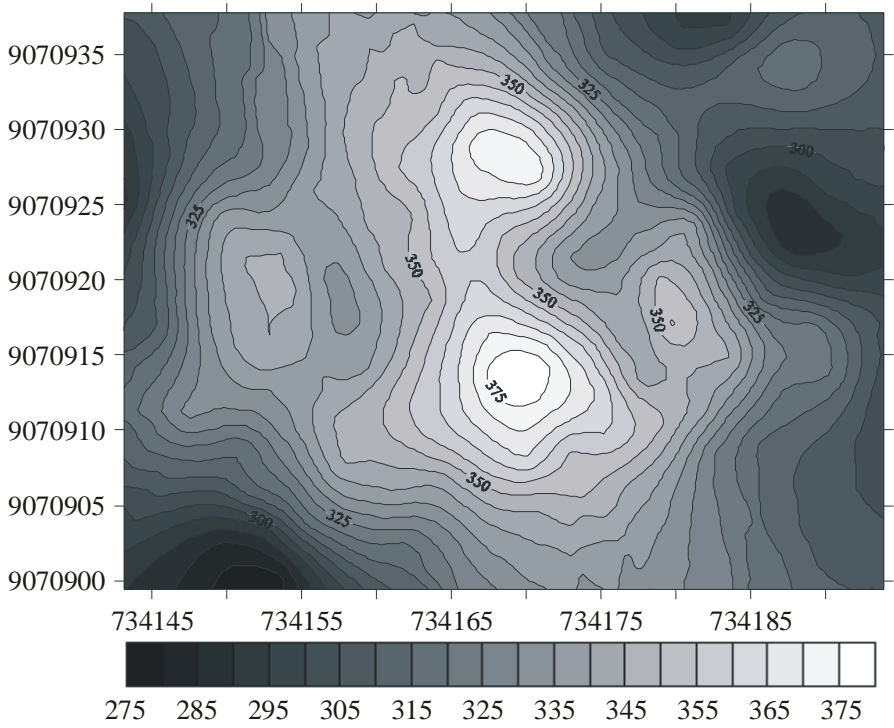

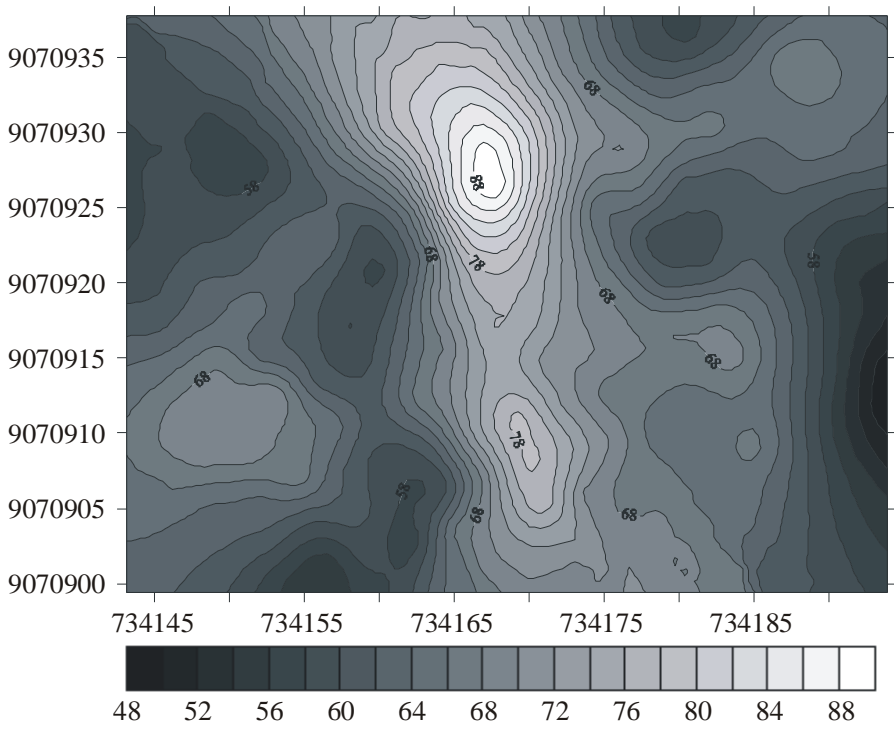

Figura 3. Semivariograma e mapa de isolinhas: (A) altura das plantas aos 200 dias após a semeadura (DAS); (B) diâmetro caulinar aos 200 dias após a semeadura (DAS)

\section{CONCLUSÕES}

1. Os atributos edáficos e de crescimento da cultura da mamona se apresentaram com baixa e média variabilidade e grau de dependência espacial, respectivamente;

2. O mapeamento da granulometria permitiu identificar as regiões com maior heterogeneidade na área de cultivo;

3. A partir do mapeamento da altura das plantas e do diâmetro caulinar, identificaram-se regiões com maior crescimento da cultura e consequente maiores produtividades correspondendo às áreas com menor teor de areia;

4. A partir do mapeamento da CEes antes e depois da estação chuvosa, observou-se sua redução após o primeiro ciclo da cultura.

\section{AGRADECIMENTOS}

Ao CNPq/CT-Agro/CT-Hidro, pelo suporte financeiro; à
UFRPE e à Embrapa Algodão - CNPA, pelo suporte logístico e institucional.

\section{LITERATURA CITADA}

Almeida Júnior, A. B., Oliveira, F. A.; Medeiros, J. F.; Oliveira, M. K. T.; Linhares, P.C.F. Efeito de doses de fósforo no desenvolvimento inicial da mamoneira. Revista Caatinga, v.22, n.1, p.217-221, 2009.

Assumpção, R. A. B.; Uribe-Opazo, M. A.; Souza, E. G.; Johann, J. A. Uso da krigagem indicatriz na avaliação da probabilidade de produtividade de graos de soja (Glicínia max) segundo os padrões regional, estadual e nacional. Acta Scientiarum, v.29, p.165-171, 2007.

Beltrão, N. E. de M.; Cartaxo, W. V.; Pereira, S. R. P.; Soares, J. J.; Silva, O. R. R. F.; O cultivo sustentável da mamona no semiárido brasileiro. Campina Grande: Embrapa CNPA, 2005. 23p. Circular técnica, 84 
Beltrão, N. E. de M.; Gondim T. M. S.; Cardoso, G. D. C.; Severino, L. S.; Queiroz, U. C.; Albuquerque, R. C. Crescimento e produtividade econômica e biológica de mamoneira, cultivares BRS 149 - Nordestina e BRS 188 - Paraguaçu, em regime de sequeiro no Nordeste Brasileiro. In: Congresso Brasileiro de Mamona: Energia e Sustentabilidade, 1, 2004, Anais...Campina Grande: EMBRAPA, 2004, CD-Rom.

Bertolani, F. C.; González, A. P.; Liñares, M. L.; Vázquez, E. V.; Miranda, J. G. V. M. Variabilidade espacial da rugosidade superficial do solo medida com rugosímetros de agulhas e laser. Bragantia, v.59, n.2, p.227-234, 2000.

Cambardella, C. A.; Moorman, T. B.; Novak, J. M.; Parkin, T. B.; Karlen, D. L.; Turco, R.F.; Fielscale variability of soils properties in central Iowa, Soils. Soil Science Society of American Journal, Madison, v.58, p.1501-1511, 1994.

Cardoso, G. D.; Alves, P. L. C. A.; Beltrão, N. E. de M.; Barreto, A. F. Uso da análise de crescimento não destrutiva como ferramenta para avaliação de cultivares. Revista de Biologia e Ciências da Terra, v.6, n.2, p.79-84, 2006.

Carvalho, J. R. P.; Vieira, S. R.; Grego, C. R. Comparação de métodos para ajuste de modelos de semivariograma da precipitação pluvial anual. Revista Brasileira de Engenharia Agrícola e Ambiental, v.13, n.4, p.443-448, 2009.

Chaves, L. H. G.; Chaves, I. B.; Vasconcelos, A. C. F.; Leão, A. B. Avaliação da salinidade dos Neossolos dos perímetros irrigados São Gonçalo e Engenheiro Arcoverde, PB. Revista Agropecuária Técnica, v.26, n.1, p.18-26, 2005.

Corá, J. E.; Araújo, A. V., Pereira, G. T.; Beraldo, J. M. G. Variabilidade espacial de atributos do solo para adoção do sistema de Agricultura de precisão na cultura de cana-de-açúcar. Revista Brasileira de Ciência do Solo, v.28, p.1013-1021, 2004.

Doorenbos, J.; Pruitt, J. O. Crop water requeriment. Rome: FAO, 1977. 144p. FAO Irrigation and drainage, Paper 24

Englund, E.; Sparks, A. Geo-EAS. Geostatistical Environmental Assessment Software. Las Vegas: International Ground Water Modeling Center. 1992. CD-Rom

Frogbrook, Z. L.; Oliver, M. A.; Salahi, M.; Ellis, R. H. Exploring the spatial relations between cereal yield and soil chemical properties and the implications for sampling. Soil Use and Management, v.18, n.1, p.1-9, 2002.

Gonçalves, A. C. A.; Folegatti, M. V.; Mata, J. D. V. Análises exploratória e geoestatística da variabilidade de propriedades físicas de um Argissolo Vermelho. Acta Scientiarum, Maringá, v.23, n.5, p.1149-1157, 2001.

Guimarães, M. M. B.; Beltrão, N. E. de M.; Lima, V. L. A. de; Costa, F. X.; Santos, J. S.; Lucena, A. M. A. Fontes de fertilizantes nitrogenados e seus efeitos no crescimento da mamoneira. Revista Engenharia Ambiental, v.5, n.3, p.203-219. 2008.

Lemos, R. C.; Santos, R. D. Manual de descrição e coleta de solo no campo. Campinas: SBCS/CNPS, 3.ed., 1996. 83p.

Lima, C. B.; Santos Filho, S. V.; Oliveira, M.; Santos, M. A. Crescimento de mamona em três solos da região de Mossoró-RN sob diferentes teores de água de irrigação. In: Congresso Brasileiro de Mamona: Energia e Sustentabilidade, 1, 2004, Campina Grande. Anais... Campina Grande: Embrapa Algodão, 2004. CD-Rom
Lima, J. A. G.; Mendes, A. M. S.; Duda, G. P.; Ferreira, C. V. Variabilidade espacial de características físico-hídricas de um Cambissolo cultivado com mamão no semiárido do RN. Caatinga, v.19, p.192-199, 2006.

Lima, R. L. S.; Severino, L. S.; Ferreira, G. B.; Silva, M. I. L.; Albuquerque, R. C.; Beltrão, N. E. M. crescimento da mamoneira em solo com alto teor de alumínio na presença e ausência de matéria orgânica. Revista Brasileira de Oleaginosas e Fibrosas, v.11, n.1, p.15-21. 2007.

Mantovani, E. C.; Queiroz, D. M.; Dias, G. P. Máquinas e operações utilizadas na agricultura de precisão. In: Congresso Brasileiro de Engenharia Agrícola, 27, 1998, Lavras. Anais. Lavras: Universitária, 1998. p.109-157.

Miranda, N. O.; Oliveira, T. S.; Medeiros, J. F. de; Silva, C. A. Variabilidade espacial da produtividade do meloeiro em áreas de cultivo fertirrigado. Horticultura Brasileira, v.23, n.2, p.260-265, 2005.

Montanari, R.; Pereira, G. T.; Marques Júnior, J.; Souza, Z. M.; Pazeto, R. J.; Camargo, L. A. Variabilidade espacial de atributos químicos em Latossolo e Argissolos. Ciência Rural, v.38, n.5, p.1266-1272, 2008.

Montenegro, A. A. A.; Montenegro, S. M. G. L. Variabilidade espacial de classes de textura, salinidade e condutividade hidráulica de solos em planície aluvial. Revista Brasileira de Engenharia Agrícola e Ambiental, v.10, n.1, p.30-37, 2006.

Nascimento, M. B. H. do; Lima, V. L. A. de; Beltrão, N. E. de M.; Souza, A. P.; Figueirêdo, I. C. M.; Lima, M. M. Uso de biossólido e de água residuária no crescimento e desenvolvimento da mamona. Revista Brasileira de Oleaginosas e Fibrosas. v.10, n.1/2, p.1001-1007, 2006.

Oliveira, M. K. T.; Oliveira, F. A.; Medeiros, J. F. de; Lima, C. J. G. S.; Guimarães, I.P. Efeito de diferentes teores de esterco bovino e níveis de salinidade no crescimento inicial da mamoneira (Ricinus communis L.). Revista Verde de Agroecologia e Desenvolvimento Sustentável Grupo Verde de Agricultura Alternativa (GVAA), v.1, n.1, p.47-53, 2006.

Panosso A. R., Pereira, G. T.; Marques Júnior, J.; Scala Júnior, N. Variabilidade espacial da emissão de $\mathrm{CO}_{2}$ em Latossolos sob cultivo de cana-de-açúcar em diferentes sistemas de manejo. Engenharia Agrícola, v.28, n.2, p.227-236, 2008.

Queiroz, J. E.; Filho, G. M. S.; Gheyi, H. R.; Santos, R. V.; Souza, L. C.; Sousa, J. R. Caracterização espacial da salinidade de um solo aluvial do projeto capoeira, estado da Paraíba. In: Congresso Brasileiro de Ciência do Solo, 27, 1999, Brasília. Anais... Brasília. SBCS, 1999. CD-Rom

Robertson, G. P. Geostatistics for the environmental sciences - GS+ User's Guide. Plainwell: Gamma Design Software, 1998. 152p.

Souza, E. R.; Montenegro, A. A. A.; Montenegro, S. M. G. L.; Santos, T. E. M.; Andrade, T. S.; Pedrosa, E. R. Variabilidade espacial das frações granulométricas e da salinidade em um Neossolo Flúvico do semi-árido. Ciência Rural, v.38, n.2, p.698-704, 2008.

Souza, L. C.; Queiroz, J. E.; Gheyi, H. R. Variabilidade espacial da salinidade de um solo aluvial no semiárido paraibano. Revista Brasileira de Engenharia Agrícola e Ambiental, v.4, n.1, p.35-40, 2000. 
Souza, M. Z.; Silva, M. L. S.; Guimarães, G. L.; Campos, D. T. S.; Carvalho, M. P.; Pereira, G. T. Variabilidade espacial de atributos físicos em um Latossolo Vermelho Distrófico sob semeadura direta, em Selvíria, MS. Revista Brasileira de Ciência do Solo, v.25, p.699-707, 2001.

Souza, Z. M.; Marques Júnior, J.; Pereira, G. T. Variabilidade espacial da estabilidade de agregados e matéria orgânica do solo sob cultivo de cana-de-açúcar. Pesquisa Agropecuária Brasileira, v.39, n.5, p.491-499, 2004.

Vauclin, M.; Vieira, S. R.; Vauchaud, G.; Nielsen, D. R. The use of cokriging with limited field soil observations. Soil Science Society of America Journal, v.47, n.1, p.175-184, 1983.
Vieira, S. R. Geoestatística em estudos de variabilidade espacial do solo. In: Novais, R. F.; Alvarez V., V. H.; Schaefer, G.R. (ed.). Tópicos em ciência do solo. Viçosa, Sociedade Brasileira de Ciência do Solo, 2000. v.1, p.1-54.

Vieira, V. A. S.; Mello, C. R.; Lima, J. M. Variabilidade espacial de atributos físicos do solo em uma microbracia hidrográfica. Revista Ciência Agrotécnica, v.31, n.5, p.1477-1485, 2007.

Warrick, A. W.; Nielsen, D. R. Spatial variability of soil physical properties in the field. In: Hillel, D. (ed.). Applications of soil physics. New York: Academic Press, 1980. Cap.2, p.319-344. 